\title{
The impact of knowledge and attitude of leprosy following a public awareness session in patients visiting dermatology out patient department
}

\author{
Ganiger Veena, Nagesha Parvathi, Nirvanappa Vinay, Ittigi Vivekananda, \\ Rangegowda Suresh
}

Department of Dermatology Venereology and Leprosy, Hassan Institute of Medical Sciences, Karnataka, India

Corresponding author: Nagesha Parvathi, MD, E-mail: drparvathicn@gmail.com

\begin{abstract}
Background: The lack of knowledge, stigma and misconception are the major barrier in leprosy control program. This study was aimed at assessing the knowledge and behavior towards the leprosy after the awareness session conducted for the patients visiting the out patient department of dermatology. Materials and Methods: Aquestionnairebasedcross sectional study was conducted on patients to evaluate knowledge and attitudes towards leprosy before and after the awareness session. Results: Total 177 subjects between age group 18 and 60 years were included. After the awareness program,knowledge about leprosy, it's cause, course, complications, treatment and attitude of the patients towards leprosy was changed positively. The difference was significant $(\mathrm{P}<0.001$, McNemar test). The knowledge regarding mode of spread,side effects of treatment did not change after the awareness program. Conclusion: The awareness session had a positive impact on study subjects in terms of knowledge and attitude towards leprosy.
\end{abstract}

Key words: Leprosy; Knowledge; Attitude

\section{INTRODUCTION}

Leprosy being one of the oldest disease known to mankind poses a major public health problem as a communicable and a social disease[1]. Stigma attached to leprosy is typically asocial process, experienced or anticipated, characterized by exclusion, rejection, blame or devaluation that result from experience, perception or reasonable anticipation of an adverse social judgment about a person or group[2]. In India leprosy was known since ancient time as 'Kustharoga' and attributed to punishment or curse from God[3]. Modern day leprosy dated from 1873 when Hansen of Norway discovered Mycobacterium leprae. With a sustained effort, India achieved the goal of elimination of leprosy in December, 2005, when the recorded prevalence rate $(\mathrm{PR})$ in the country was $0.95 / 10,000$ population [3]. A variety of educational activities such as small group talks, posters, and use of catchy slogans will help the people to get awareness regarding the disease[3].

Despite the so many national public awareness programs the misconception regarding the course and treatment of the disease has lead to the invariable social stigma. Raising awareness in communities regarding early leprosy symptoms, engagement of private health care provider in early leprosy diagnosis in high endemic areas may help in reducing diagnosis delays[4].Even after introduction of multidrug therapy, most of the rural population were not motivated enough for seeking help in diagnosis and treatment[5].To reduce stigma related to leprosy, an emphasis needs to be placed on education regarding transmission and the low rate of infectivity of leprosy [6,7]. The aim of this study was to know the knowledge and behavior towards the leprosy patients after the public awareness session conducted for the patients visiting the department

\footnotetext{
How to cite this article: Veena G, Parvathi N, Vinay N, Vivekananda I, Suresh R. The impact of knowledge and attitude of leprosy following a public awareness session in patients visiting dermatology out patient department. Our Dermatol Online. 2021;12(e):e81.

Submission: 02.02.2021; Acceptance: 08.07.2021

DOI: 10.7241/ourd.2021e.81
} 
of Dermatology, Venereology and Leprosy out patient department. This study will help to understand the knowledge, attitude and practices of the general public in regards to leprosy and provides an important message for the health sector to adapt the effective measures to improve the national leprosy programs.

\section{MATERIALS AND METHODS}

A cross sectional observational study was conducted on patients visiting Department of Dermatology, Venereology and Leprosy, Hassan Institute of Medical Sciences, Hassan on a specified day of the week and duration of the study was 1 month. The study subjects included were patients more than 18 years of age of either sexes and patients who did not give consent for the study were excluded.

Public awareness in terms of informative talks, slogans, notes and printed informative sheets was given. The information was in local language Kannada and it mainly concentrated on the cause of the disease, mode of spread, course, signs and symptoms, complication and treatment of leprosy. The program was an open end discussion where study subjects were encouraged to ask and clear their doubts regarding the disease. Data was collected using a closed ended questionnaire in local language Kannada, which was designed to evaluate knowledge, perceptions and attitudes regarding leprosy. A set of questionnaire was given to the study subjects each before and after the awareness program which consists of 15 questions which includes questions regarding knowledge, attitude and practice regarding the disease. For subjects who express their inability to read the questionnaires was dictated in their understandable language. The demographic data of the study subjects in terms of name, age, sex, educational qualification and occupation was collected. At the end of the awareness program the study subjects were encouraged to share their experiences. The data was compiled, analysis was done using SPSS version 20.

\section{Ethics Statement}

Ethical committee clearance was taken.

\section{RESULTS}

Table 1 shows the demographic data. Total 177 subjects included in the study among which 38 were males and 139 were females. Age group included in the study were between 18 to 60 years. Most of the patients were from urban area (99) compared to rural area(78). Majority had completed their college (72) and primary schooling (70) and 20 were uneducated.

Before and after awareness program knowledge regarding leprosy was assessed using questionnaire. Table 2 shows assessment of knowledge. 92 in the pre awareness session and 129 in the post awareness session had opinion that leprosy is contagious. The difference was statistically significant $(\mathrm{p}=<0.001)$. 76 participants in the pre awareness session and 49 in the post session had opinion that leprosy is hereditary disorder. 80 participants in pre session and 81 in post session had opinion that leprosy spreads by touch and the difference between them was statistically insignificant $(\mathrm{p}=1) .54$ in the pre session and 34 in the post session had opinion that all light colored skin patches can be because of leprosy and the difference was statistically significant. Regarding the treatment 34 in pre session and 43 in post session had the opinion that leprosy can be cured without treatment. The difference was statistically significant $(\mathrm{p}=0.009) .149$ in both pre and post session had opinion that leprosy can be cured completely. 122 in pre session and 121 in post session had opinion that leprosy can be spread to children. 143 in pre session and 174 in post session had opinion that leprosy can cause physical disability and the difference was statistically significant. 169 in pre session and 177 in post session were aware of the fact that treatment for leprosy is freely available. 91 in pre session and 121 in post session had opinion that leprosy treatment has side effects. 53 in pre session and 85 in post session had opinion that leprosy can be cured in short time period. 128 in pre session and 73 in post session had opinion that Leprosy can reoccur even after complete treatment.

Table 1: Demographic data

\begin{tabular}{llc}
\hline Attributes & Category & No $(\%)(\mathrm{N}=177)$ \\
\hline Age & $<19$ years & $87(49.15)$ \\
& $20-40$ years & $28(15.8)$ \\
Sex & $>40$ years & $62(35)$ \\
Education & Male & $38(21.4)$ \\
& Female & $139(78.3)$ \\
& Primary school & $70(39.5)$ \\
& Secondary school & $15(8.4)$ \\
Occupation & College & $72(40.6)$ \\
& Uneducated & $20(11.3)$ \\
& Student & $27(15.2)$ \\
& Housewife & $80(45.19)$ \\
& Skilled labourers & $1(0.56)$ \\
Demographic area & Unskilled labourers & $49(27.6)$ \\
& Professionals & $21(11.8)$ \\
& Rural & $78(44)$ \\
& Urban & $99(55.9)$ \\
\hline
\end{tabular}


Table 3 shows assessment of attitude. 46 in pre session and 39 in post session had opinion that Leprosy is caused by past sins and the difference was statistically insignificant $(\mathrm{p}=0.34) .71$ in pre session and 37 in post session had opinion that Leprosy occurs only in lower socioeconomic class people and it was statistically significant $(p=0.001)$. All 177 participants had opinion that Leprosy patient can lead a normal life after complete treatment before and after the awareness session.

\section{DISCUSSION}

This study was conducted to know the knowledge and behavior towards the leprosy patients after the public awareness session conducted for the patients visiting the Department of Dermatology, Venereology and Leprosy out patient department. Total of 177 subjects of both the sexes with age group between 18 to 60 years included in the study.

Most of the participants did not have knowledge about causal agents which they thought it is a hereditary disorder (76), mode of spread (80), chance of infection to others from leprosy (97) before the awareness program. Similarly, few patients had a belief that leprosy was associated with past sins (46) and it occurs in only lower class people (71). The attitude towards leprosy was changed positively after awareness session in our study.

T Stephen, I Selvaraj et al [1]2014, conducted a questionnaire based study on leprosy patients and family members which showed that they had adequate average level of knowledge about leprosy, but their attitude toward the disease and their practices were not adequately favorable.

In a study by Saha et al [3] it was found that few patients thought leprosy to be associated with divine curse $(13 \%)$ and patient's own fault $(22.7 \%)$. A sizable number of patients $(21 \%)$ said that leprosy was caused by curse, sin, heredity or bad blood.

Majority of the participants had a knowledge regarding the treatment its availability, side effects and duration of treatment.

A study by Earnest NjihTabah, et al [8] 2018, on community knowledge, perceptions and attitudes regarding leprosy in rural Cameroon showed that an awareness intervention using community volunteers and the media, with information on the cause of leprosy, its clinical manifestations and curability, and sensitization messages correcting the misconceptions and beliefs regarding leprosy, could improve the community knowledge and attitudes towards leprosy.

Doulat Rai Bajaj, Bhajan Lal Matlani et al [9], conducted a study on 200 doctors among them 14 doctors $(7 \%)$ had poor knowledge of disease and $140(70 \%)$ doctors had good knowledge of the disease. The study conveys that there is deficient knowledge regarding of leprosy among general practitioners, which needs to be improved by conducting awareness activities.

Table 2 : Knowledge about leprosy

\begin{tabular}{|c|c|c|c|c|c|}
\hline Attributes & Pre test -yes & Pre test- no & Post test yes & Post test no & $P$ value \\
\hline 1. Leprosy is contagious & 97 & 80 & 129 & 48 & 0.001 \\
\hline 2. Leprosy is a hereditary disease & 76 & 101 & 49 & 128 & 0.001 \\
\hline 3. Leprosy spreads by touch & 80 & 97 & 81 & 96 & 1 \\
\hline 4. All skin patches can be leprosy & 54 & 123 & 34 & 143 & 0.002 \\
\hline 5. Leprosy gets cured without treatment & 34 & 143 & 49 & 129 & 0.009 \\
\hline 6. Leprosy can be cured completely & 149 & 28 & 149 & 28 & 1 \\
\hline 7. Leprosy can spread to children & 122 & 55 & 121 & 56 & 1 \\
\hline 8. Leprosy can cause physical disability & 143 & 34 & 174 & 4 & 0.001 \\
\hline 9. The treatment for leprosy is freely available & 169 & 8 & 177 & 0 & - \\
\hline 10. The treatment for leprosy has side effects & 91 & 86 & 102 & 75 & 0.22 \\
\hline 11. Leprosy can be cured within short time & 53 & 124 & 85 & 92 & 0.001 \\
\hline 12. Leprosy can reoccur even after complete treatment & 128 & 49 & 73 & 104 & 0.001 \\
\hline
\end{tabular}

Table 3 : Attitude towards leprosy

\begin{tabular}{|c|c|c|c|c|c|}
\hline Attributes & Pre test yes & Pre test-no & Post test-yes & Post test-no & $P$ value \\
\hline Leprosy is caused by past sins & 46 & 131 & 39 & 138 & 0.349 \\
\hline Leprosy occurs only in lower class people & 71 & 106 & 37 & 140 & 0.001 \\
\hline Leprosy patient can lead a normal life after complete treatment & 177 & 0 & 177 & 0 & \\
\hline
\end{tabular}


Seshadri D, Khaitan BK [10], et al 2014, conducted a study of knowledge and attitude towards leprosy on 260 subjects ( 100 leprosy patients, 60 family members of leprosy patients and 100 people with non-leprosy skin diseases). The study showed Knowledge and attitude towards leprosy are unsatisfactory.

According to our study there was positive change observed among the participants following awareness program with respect to the cause of leprosy its course and complications, availability of treatment. In the assessment of attitude towards leprosy it was observed that the awareness program has helped the patients to improve their attitude positively. The difference was highly significant $(\mathrm{P}<0.001$, McNemar test $)$. The knowledge regarding mode of spread, side effects of treatment did not change after the awareness program.

\section{CONCLUSION}

The awareness session had a positive impact on study subjects in terms of knowledge and attitude towards leprosy which will help community members to contribute to the reduction of leprosy burden in the community.

\section{REFERENCES}

1. Stephen T, Selvaraj I and Parmeswari PJ. Assessment of knowledge, attitude and practice about leprosy among patients and their families in a rural community in Tamil Nadu. Indian J Lepr. 2014;86:7-14.

2. Scambler G. Health-related stigma. Sociol Health and Illn.2009;31:441-55.

3. Saha G, Mandal NK,Dutta RN. Current perceptions \& practices (KAP) about Leprosy among leprosy patients: a comparative study between high prevalent and low prevalent districts of West Bengal. Indian J Lepr.2015;87:1-16.

4. Muthuvel T, Govindarajulu S, Isaakidis P, Shewade HD, Rokade V, Singh R, et al. "I wasted 3 years, thinking it's not a problem": Patient and health system delays in diagnosis of leprosy in India: a mixedmethods study. PLoSNegl Trop Dis.2017;11:e0005192.

5. Niranjan A. A cross sectional study on beliefs, attitudes, misconceptions and knowledge of patients \& community towards leprosy in and around rural areas of guntur district.IOSR J Pharm.2017;12:8-12.

6. Wijeratne MP, Ostbye T. Knowledge, attitudes and practices relating to leprosy among public health care providers in Colombo, Sri Lanka.Lepr Rev. 2017;88:75-84.

7. Indira D, Srinivas M, SangeethaJ.Community based study of knowledge, attitude and practices towards leprosy in an urban slum in Secunderabad, Telangana. J Med Science Clin Res.2016;4:13527-31.

8. Tabah EN, Nsagha DS, Bissek A-CZ-K, Njamnshi TN, Niih IN-N, Pluschke G, et al. Community knowledge, perceptions and attitudes regarding leprosy in rural Cameroon: The case of Ekondotiti and Mbonge health districts in the South-west Region PLoSNegl Trop Dis. 2018;12:e006233.

9. Bajaj DR, Matlani BL, Soomro FR, Iqbal MP. Knowledge, attitude and practices regarding leprosy among general practitioners at Hyderabad. J Coll Physicians Surg Pak. 2009;19:215-8.

10. D Seshadri, BK Khaitan, N Khanna, R Sagar.The tangled web: a study of knowledge and attitude towards leprosy from a tertiary care hospital in India. Indian J Lepr. 2014;86:27-41.

Copyright by Ganiger Veena, et al. This is an open access article distributed under the terms of the Creative Commons Attribution License, which permits unrestricted use, distribution, and reproduction in any medium, provided the original author and source are credited.

Source of Support: Nil, Conflict of Interest: None declared. 